\title{
A ADOLESCÊNCIA GENERALIZADA COMO EFEITO DO DISCURSO DO CAPITALISTA E DA ADULTEZ ERODIDA
}

\author{
LA ADOLESCENCIA GENERALIZADA COMO EFECTO DEL DISCURSO \\ CAPITALISTA Y DE LA VIDA ADULTA EROSIONADA \\ THE ADOLESCENCE GENERALIZED AS A EFFECT OF THE CAPITALIST \\ DISCOURSE AND OF THE ADULT FORM ERODED
}

\author{
Marcelo Ricardo Pereira \\ Universidade Federal de Minas Gerais, Belo Horizonte/MG, Brasil
}

Rose Gurski

Universidade Federal do Rio Grande do Sul, Porto Alegre/RS, Brasil

\begin{abstract}
RESUMO
A noção de que vivemos em tempos de adolescência generalizada coloca em questão tanto o que diz respeito a formas contemporâneas do laço social quanto o conceito de adolescência em psicanálise para interpretá-las. As novas configurações produzem o empobrecimento do espaço público como sítio de construção de experiências. Destacamos como um dos efeitos de tal empobrecimento a disseminação do "discurso capitalista", que não promove o laço social, ao contrário, promove uma ilusão de completude ao nivelar sujeito e objeto. Essa espécie de curto-circuito produzido pelas práticas da cultura leva também à idealização do lugar da adolescência como tempo sublime da existência, a ser eternizado, e que resulta em um paradoxo de difícil solução por parte do jovem para atravessá-lo. Se todos querem eternizar o lugar da juventude, quem vai ocupar o lugar do adulto na relação com os adolescentes?
\end{abstract}

Palavras-chave: adolescência; laço social; experiência; tempo; discurso capitalista.

\section{RESUMEN}

La noción de que vivimos en tiempos de adolescencia generalizada plantea interrogantes tanto en lo relativo a las formas contemporáneas de lazos sociales como en el concepto de la adolescencia en el psicoanálisis para interpretarlos. Las nuevas configuraciones producen el empobrecimiento del espacio público como sitio de construcción de experiencia. Distinguimos como uno de los efectos de tal empobrecimiento la propagación del "discurso capitalista", que no promueve el lazo social, por el contrario, promueve una ilusión de plenitud al nivelar el sujeto y el objeto. Este tipo de cortocircuito producido por las prácticas de la cultura también conduce a la idealización del lugar de la adolescencia como un tiempo sublime de la existencia, para ser eternizado, y que da lugar a una paradoja difícil de resolver por los jóvenes. Si todos quieren eternizar el lugar de la juventud, ¿quien tomará el lugar del adulto en la relación con los adolescentes?

Palabras clave: adolescencia; lazo social; experiencia; tiempo; discurso capitalista.

\begin{abstract}
The notion that we are living in a time of generalized adolescence brings into question both as regards contemporary forms of social ties and the concept of adolescence in psychoanalysis to interpret them. At the present, new configurations induce an impoverishment of the public space as a place for building experience. We highlight as an effect of such impoverishment the dissemination of the "capitalist discourse". This does not promote social ties, but an illusion of completeness leveling subject and object. This kind of short circuit produced by cultural practices leads also to an idealization of the adolescence as a sublime time within existence, being eternalized, and that results in a paradox difficult to solve by the youth to cross it. If everyone wants to stay forever young, who will take the place of the adult in the relationship with teens?
\end{abstract}

Keywords: adolescence; social bond; experience; time; capitalist discourse. 
A centralidade do "ser" jovem é crescente em nossa cultura. A idealização da adolescência como período pleno de realizações tem se estabelecido como uma das mais pródigas perspectivas, tanto para a infância como para a adultez. Segundo o refrão de um videoclipe realizado a partir de pesquisa de referência acerca do adolescente brasileiro, os jovens ${ }^{1}$ têm sido catalisadores das grandes mudanças, resultando assim no que eles mesmos insistem em dizer: "para entender o mundo, é preciso compreender os jovens" ${ }^{2}$.

De fato! Compreendê-los passou a ser um dos imperativos contemporâneos para se entender o mundo em que vivemos. Nesse sentido, a célebre e visionária máxima de Bob Dylan, Forever young, não se limitou a ser apenas uma canção de protesto, extraída dos movimentos da contracultura, mas um modo invocador de nos impelir a sermos para sempre jovens ${ }^{3}$. E aqui temos uma questão repleta de inquietação, pois, se todos querem ser ou ficar para sempre jovens - como sugere a canção -, quem vai ocupar o lugar do adulto na relação com os adolescentes? Como lembra Maria Rita Kehl (2004), se dos 18 aos 40 anos todos são "jovens", em que resulta esse apagamento da diferença geracional que ora julgamos tão importante para a constituição do sujeito na sua condição adolescente ${ }^{4}$ ?

A noção de vaguidade do lugar do adulto, ou ainda, a de que estamos frente a um tempo de adolescência generalizada (Gurski, 20115; Pereira, 2011) não é questão apenas para psicanalistas. Eric Hobsbawn (2002), o importante historiador contemporâneo, falecido no ano de 2012 - a quem prestamos justa menção e homenagem -, sugeria que o século XX foi o século da adolescência. Segundo ele, a repercussão do modus vivendi dos jovens, exportado pela cultura americana através do cinema e das novas estratégias de apelo ao consumo, nos levou a viver em uma cultura juvenilizada, na qual o adolescente tornouse o paradigma de crianças e adultos. Nesse diapasão, o historiador também afirma que a juventude, a partir da década de 60, consolidou-se como um segmento social próprio, sendo esse período reconhecido como um tempo histórico e pioneiro na dose de importância que concedeu ao adolescente.

Dentre as variáveis que participam desse quadro, devemos considerar também o tipo de discurso que compõe o laço social atual. Ora, a causa para vivermos em tempos de violência fria e apatia indiferenciada talvez resida, em parte, na "nostalgia do pai" ou na impossibilidade de fazermos o luto de ideologias que demarcaram nossa entrada na mística moderna, sob efeitos do brasão "Liberdade, Igualdade e Fraternidade".
Essa seria uma das razões para esses tempos melancólicos, pós-revolucionários, caracterizados pela suspensão do desejo, pela apatia, pelo transbordamento do gozo que visa apenas à satisfação pessoal, imediata e vazia. Muitas das antigas ilusões foram enterradas e, sem elas, acabamos desembocando num mundo da ordem politicamente correta, cuja ilusão suprema parece ser a ausência de ilusões e de utopias. No lugar delas, emerge o pseudoconsenso individualista e apolítico, em que todas as coisas são emparelhadas, sem profundidade e sem adensamento.

A vida nas cidades, própria desses tempos, é caracterizada por duas forças contraditórias: de um lado, o excessivo planejamento e métrica da vida social; do outro, o descontrole do espaço urbano e a perda da noção de totalidade das experiências sociais. Em ambos os casos, as subjetividades são asfixiadas, mas tendem a ressurgir violentas, fragmentárias, em atitudes individualistas e pseudolibertárias. A massificação do estilo de vida e a valorização do imediato contribuem para transformar tais atitudes em cultura do espetáculo, em inflação de narcisismos, mas raramente em reflexão crítica e luta política.

É nesse cenário - e o termo não é sem razão - que nossos jovens constituem suas subjetividades. Trata-se de um cenário polifônico, contraditório e instável em que, por meio de "tribos" urbanas, ídolos e modismos, o adolescente exercita as relações, cria códigos de comunicação e atitudes. Porém, alerta Oliveira (s.d.), ao igualar-se a seus pares para diferenciar-se dos demais, todo jovem confronta-se com imagens ilusórias que podem favorecer comportamentos de risco e acirramento das divergências sociais. Na medida em que os espaços públicos tornam-se arriscados e ameaçadores, é comum vermos jovens refugiarem-se e submeterem-se à tirania de suas tribos ou de suas redes sociais.

Mas há outro aspecto que convém destacar: acreditamos que tal cenário e tais atitudes apresentamse como efeito do que em Psicanálise se denomina "discurso capitalista" (Lacan 6 , 1972). Esse discurso não promove propriamente o laço social, mas, ao contrário, através de uma parceria desconectávela-qualquer-momento, promove uma ilusão de completude ofertando ao sujeito objetos de consumo curtos, rápidos e descartáveis - ainda que isso gere tédio, tristeza, falta de sentido na mesma velocidade em que são consumidos. $\mathrm{O}$ adolescente da atualidade se vê, então, entre o imperativo macrofísico do capital e o imperativo microfísico de sua tribo, de sua rede, que por sua vez usam o capital para fixá-lo a essa tirania. Isso porque o discurso do capitalista produz segregação: única maneira com a qual nossa sociedade 
vem tratando as diferenças. Vejamos como isso se apresenta.

\section{O discurso do capitalista e o jovem}

Partimos do pressuposto de que o adolescente pode ser tomado como o sujeito paradigmático do seu tempo social. Ávido, do ponto de vista estrutural, pela construção de novos nomes do pai - nomes através dos quais se organizam a lei e o desejo -, ele busca profundamente na cultura de seu tempo, e em seus dispositivos, motes de inspiração para a constituição de outras significações de si. Eis, portanto, um tempo revelador da torção irredutível entre o social e o psíquico - atualmente parece tratar-se de um tempo cimentado sob a égide dos valores e conceitos do capitalista.

Nesse sentido, não é demais lembrar do quanto se amplificam as chances de tal irredutibilidade impregnar a subjetividade juvenil. Lacan (1972, 1974/1996), quando retomou o escrito $O$ mal-estar na civilização, de Freud (1930/1980b), considerou-o um livro fundamental para se entender o discurso do capitalista e a ordem contemporânea de imperativo de gozo (superegoico). Indubitavelmente, vivemos em tempos nos quais os bens tornaram-se nosso mestre, conduzindo atitudes e induzindo ao consumo fugidio de objetos produzidos pelo capitalismo científicotecnológico. Diferentemente do que o próprio Lacan afirmara alguns anos antes (1969-70/1992), dizendo ser o discurso da universidade o próprio discurso do mestre moderno, temos de admitir, em tese, que o laço social que domina a atualidade é aquele que o desenlaça, a saber, o discurso do capitalista.

\section{Discurso do mestre}

$$
\begin{array}{lll}
\underline{\mathrm{S}}_{1} & \rightarrow & \underline{\mathrm{S}}_{2} \\
\$ & / / & \mathrm{a}
\end{array}
$$

Discurso do capitalista

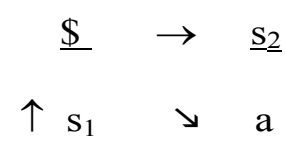

Ou seja, Lacan apresenta o discurso do capitalista como um "deslizamento" do discurso do mestre, que, como tal, se autoriza como significante-primordial $\left(\mathrm{s}_{1}\right)$ a obter do governado $\left(\mathrm{s}_{2}\right)$ a produção de objetos fabricados para seu usufruto: objetos de gozo (a).
Esse $\mathrm{s}_{1}$ é um significante que legifera, sentencia e determina a castração. Ele subordina o outro e o obriga a uma exigência de identidade única ou a "ser um". Nesse sentido, mesmo sem admitir a diferença entre os homens, o discurso do mestre regula as relações sociais. Porém, o discurso do capitalista, ao contrário do discurso do mestre, não regula o laço social, ele é um discurso sem lei, que conclui (rejeita) a castração e que, por isso, produz segregação.

De inspiração marxista, o discurso do capitalista - uma espécie de quinto discurso da álgebra lacaniana - foi um artifício do autor para demonstrar como o sujeito se acha fixado ao objeto e, ao mesmo tempo, sujeitado a nada, senhor das palavras e das coisas, sem dívida com a lei ou com os outros homens. Para forjar o algoritmo do capitalista, Lacan inverte as posições do $\mathrm{s}_{1}$ e do $\$$ que o discurso do mestre apresenta. Sublinha que há, no mínimo, um caráter perverso naquele que agencia tal discurso, pois um imperativo de gozo ou de desregramento pulsional o ordena. Ele faz o outro desaparecer por detrás da massificação dos objetos, da erosão das relações políticas, do apagamento da diferença geracional, do consumo hedonista, da sua necessidade de satisfação pulsional sem mediação. $\mathrm{O}$ capitalista faz produzir objetos de gozo (mais-gozar) tanto para si quanto para o outro que tenha capital para consumi-los. Eis o fetichismo da subjetividade - modo maior de exercermos a segregação.

Nesse sentido, entendemos que os adolescentes - como qualquer um de nós - vivem e são educados para uma sociedade que os objetaliza, induzindo-os ao individualismo consumista, a gadgets ou a objetos de gozo que obedecem a um imperativo do "ter" para não "serem" segregados e alijados na circulação social. Pela imensa dificuldade de acessarem o "ter" de uma sociedade excludente, esses jovens tribalizados (Maffesoli, 1998) produzem novos modos de sintoma e novos males que requerem novos saberes e objetos produzidos pela tecnologia capitalista.

Tais jovens se rotulam facilmente, entre tantos, de Punks, Funks, Hippies, Hip-hops, Emos, Clubbers, Góticos, Skatistas, Skinheads, ao lado de grupos religiosos, sociais e políticos igualmente sectários. Tais tribos eminentemente urbanas não deixam de expressar sua insatisfação com a ordem do capital, entretanto, não deixam também de empregar o mesmo dispositivo do qual essa ordem faz uso: a segregação. É comum funcionarem como célula autônoma, de caráter fundamentalista, exercendo intolerância e exclusão (Pereira, 2006).

Os jovens de hoje parecem tentar, desesperadamente, estabelecer uma possível demarcação como diferente do adulto-racional-padrão, 
demonstrando com isso a percepção da ausência de distância geracional. Assim sendo, mostram-se também pouco confortáveis em relação ao mundo em que vivem, pois ora transitam como diferente-sublime, ora como diferente-repulsivo, isto é, ora como diferenteidealista, ora como diferente-dejeto. Em regra, para expressarem isso, acabam por mostrar alguma forma de cinismo, escárnio, indisciplina, desvio de conduta, violência, hipersexualização, ao lado de marcas no corpo, patologias narcisistas e depressão.

A clínica e a investigação acadêmica testemunham que, muitas vezes, tais expressões não querem outra coisa senão ofertar-se como osso de resistência à moral adulta que se diz padrão. Mediante a arbitrariedade do "grande" em querer tudo normalizar, a maioria dos jovens não se deixa vergar facilmente. Se a moral adulta pode submeter o infantil com menos obstáculos, no jovem ela conhecerá mais detidamente essa resistência. $\mathrm{O}$ mundo é escarnecido por ele, que não vê nas velhas fórmulas dos adultos uma saída para os impasses de sua própria existência. Eles ainda têm a favor de si - não como vantagem, mas como dianteira - os transbordamentos do mundo contemporâneo produzidos pelo discurso do capitalista: domínio tecnológico, excesso de consumo, sectarismo grupal, recursos profanos, voyeurismo imagético, hipervalorização da vida privada ou, em outras palavras, formas de gozo menos recalcadas.

Outra questão fundamental é o surgimento de uma sociedade aceleradamente tecnológica, que é bastante dominada pelos jovens, mas nem tanto pelos adultos que os guiam - incluindo pais e professores. Esses adultos, em geral, não foram formados para tal sociedade. Sua experiência como infantes e jovens que foram não são as mesmas que as novas gerações estão vivenciando. A "modernidade tardia", além de trazer desconcertantes mudanças de atitude, de fragmentar hábitos e valores, abriu um espaço abissal contra toda e qualquer condição precedente. Ora, uma sociedade mais complexa, mais evoluída tecnicamente, estabelecida pela moral capitalista, exige, cada vez mais, um período maior para que os sujeitos possam adquirir conhecimentos necessários e protagonizar sua condução. Mas a tecnologia não é acessível a todos. Eis outra ambiguidade que é vivida pelo jovem de forma pouco apaziguada: de um lado, uma sociedade mais tecnológica produzida pelo discurso capitalista que requer mais tempo para que seus membros se formem para dela participarem; do outro, ela os exclui, tornando-os refém e ávidos em não se sentirem segregados.

Nesse sentido, perguntamos: a consolidação de uma sociedade calcada no discurso do capitalista poderia estar diretamente ligada a uma espécie de adolescentização da cultura?

\section{A adultez erodida e a adolescentização da cultura}

Se na tribuna dessa sociedade temos, de um lado, os jovens, temos, do outro, os adultos, grupo composto por pais, educadores e especialistas. É impossível deixar de notar o quanto todos eles escondem pouco suas queixas, frustrações e inabilidades em lidar com esse choque geracional. Por mais que se possa admitir que o "adolescente que não se revolta é um enfermo", as queixas apontam para o quanto está sendo difícil lidar com os vários nomes e formas dessa revolta.

Ou seja, os jovens já se sentem em condição de ensinar algo a alguém; são idealistas, querem mudar o mundo dos mais velhos, não se reconhecem mais como infantis. Porém, ressentem-se do vácuo dessa impossibilidade, mostrando-se ambivalentes quanto às suas atitudes.

Sabemos, desde Freud (1905/1980c), que a adolescência é uma espécie de efeito Nachträglichkeit (a posteriori) da sexualidade infantil: é seu retorno e também seu desenlace. O jovem se vê mediante três destinos inevitáveis e intimamente ligados entre si: (a) a desidentificação em relação aos pais ou aos objetos primordiais de amor; (b) o declínio do autoerotismo ou das formas narcísicas de investimento em tais objetos; e (c) a inscrição social de sua própria sexualidade, confrontando-se, ao dar às costas à polimorfia perversa de sua condição infantil, com a diferença dos sexos e com a angústia da castração. Entretanto, Freud antevira que tais destinos nunca se dão a contento e resultam sempre em ambivalências.

Tais ambivalências podem ser notadas em formas de ressentimento que adolescentes expressam por ainda não serem suficientemente autônomos para gerir seus próprios destinos, para declinar das formas narcísicas de satisfação pulsional e, tampouco, para evitar estar sempre ao sabor do gozo imperativo do Outro real', o adulto, que lhe diz: "está na hora de você ser alguma coisa".

Eis um dilema. Se, de maneira geral, o jovem teve a ilusão de ter sido algo para alguém quando era criança - um objeto de satisfação do adulto -, ao crescer essa ilusão não o acompanha. Sabemos que um dos dramas da operação psíquica da adolescência reside exatamente na constituição de um lugar desde o qual o sujeito possa se representar no social, um lugar que seja diferente do tutelamento recebido pelo laço com os chamados Outros reais na infância. 
Ou seja, se a criança foi supostamente idealizada, cuidada e desejada pelo desejo dos pais ou de quem os substitui - o que é uma ilusão -, o jovem dia após dia parece ter que construir novos traços de si passíveis de o representarem no laço social. Um dos paradoxos desse momento consiste no fato de que, aos olhos do adulto, ele deve ser mais autônomo, mais estudioso, mais comprometido, ser educado, cumprimentar polidamente as pessoas, dormir menos, arranjar mais dinheiro, ficar menos horas no computador ou menos tempo na rua à toa, em síntese, ele deve "se virar."

Os adolescentes acabam, portanto, vítimas de uma espécie de paradoxo cultural, pois lhes é exigido que, simultaneamente, atendam aos ideais de adequação e de inovação. "Seja rebelde, seja original" é um destes imperativos paradoxais com os quais se defrontam em meio à difícil operação psíquica que lhes concerne.

Pressionado a ter autonomia, e se bem ou mal consegue alguma, ele vive receando perdê-la, uma vez não sendo como um adulto que se mantém. Quando esse adulto lhe diz "está na hora de você ser alguma coisa", isto é, está na hora de você ser algo desejável para que meu desejo o deseje, surge então um tensionamento, muitas vezes, insuportável para o sujeito. Talvez venha daí sua identificação com o diferente-dejeto. Ao ser fixado no lugar de dejeto, o jovem responde à inadequação que o grande lhe imputa através da tribalização - quando não através da toxicomania, hipersexualização, marcas no corpo, cinismo, déficit de atenção, transtornos mentais e até como discute Freud (1910/1980a) - o suicídio.

Provavelmente, não seja absurdo pensar que muitas dessas respostas são provocações endereçadas ao adulto, não só com a finalidade de escarnecê-lo ou de injuriá-lo, mas com o fim de "paralisá-lo", de fazêlo não avançar mais - mediante a impossibilidade de o adolescente ter alguma resposta sobre seu dilema de ser algo desejável para alguém.

É preciso sublinhar que os efeitos de grupo garantem-lhes algum êxito nessa empreitada. Há um isomorfismo grupal que faz cada jovem se parecer em atitudes, gestos, vestuário e gostos com os seus pares. A turma da rua, as comunidades de Orkut, Facebook, blogs e Msn, na Web, os jogos eletrônicos, a compulsão consumista, os bailes de periferia dão-nos testemunhos do quanto os jovens vão se enquadrando num padrão prescrito, no qual as diferenças se confundem, os laços se empobrecem, os excessos se generalizam, como parece requerer a ordem capitalista. Não temos aqui uma igualdade propriamente política, mas, sobretudo, comportamental. Ainda assim, por mais que haja dilemas juvenis na atualidade, o mundo dos excessos hiperindividuais parece estar moldado para eles.

Como se faz notar, nas últimas décadas, parece indiscutível afirmar que a juventude tem-se transformado em uma espécie de ícone, de paradigma ideal para o mundo adulto. Neste diapasão, vemos também uma espécie de constrição do tempo: o envelhecimento, que outrora era signo de experiência acumulada, símbolo de sabedoria e do mais alto valor do sujeito, transformou-se em um grande sofrimento. O discurso atual faz da centralidade do corpo e da imagem jovem os índices de valor e de sucesso do sujeito.

Nesse sentido, uma porção de paradoxos convive de mãos dadas. Kehl (2004) argumenta que, ao pousar o olhar no adolescente como ideal de perfeição de nossa época, o adulto acaba por produzir um estado de desamparo que pouco permite ao jovem se orientar minimamente na vida e no mundo, já que esse ideal aponta para um excesso de presente, não balizando uma perspectiva de futuro. A disseminação do ser jovem acaba colocando todos em uma mesma posição, questão que parece retirar a dose de alteridade geracional tão necessária ao adolescente que, recémchegado da infância e das mutações pubertárias, inaugura suas primeiras inscrições na esfera pública e social.

Desse modo, além da "moratória" adolescente - que joga o jovem em uma espécie de limbo social -, eles acabam percebendo que os adultos próximos, ao sonharem com a eterna juventude, além de deixarem seu lugar vago, não se furtam em apagar as marcas do tempo e da origem, rompendo o elo que liga passado, presente e futuro. Assim, além das dificuldades próprias do adolescer, se somos uma "cultura de jovens há mais de 40 anos" (Kehl, 2004, p. 90), como fazem os adolescentes de hoje para diferenciar-se de seus genitores e formular algo novo e próprio?

Temos visto em suas expressões que a adolescentização da cultura não permite, muitas vezes, a distância necessária para a criação do novo ${ }^{9} \mathrm{em}$ termos subjetivos. Arendt (2001), no texto "A crise da educação", pondera que toda educação necessita de uma dose de conservadorismo. Isto é, será somente no encontro com o velho que o jovem, a geração que chega, poderá construir o novo. Ora, no momento em que os adultos de uma sociedade se adolescentizam através de comportamentos e condutas e que os ideais do imaginário cultural passam a valorizar a juventude e seus atributos, é como se todos constituíssem uma comunidade de iguais, desaparecendo a dose de distância geracional necessária para emergir o novo da geração vindoura. 
$\mathrm{O}$ adulto adolescentizado acaba por operar uma espécie de esvaziamento da experiência, da memória e da lei. Descartando o passado, em nome da juventude eterna, estabelece-se um vazio difícil de ser suportado, com efeitos tão nocivos à edificação de si mesmo a ponto de os jovens produzirem respostas que tentam imobilizar o adulto e sua voraz vontade de não admitir a diferença. Referimo-nos, por exemplo, a um pai cujos comentários cúmplices feitos ao filho acerca de sexo, droga ou mesmo com relação às atitudes subversivas diante de um conflito escolar, coloca-se em igualdade de posição com o jovem. Porém, enganamo-nos ao achar que o adulto só deseja a perenidade de sua condição juvenil, a beleza eterna ou a repetição do ato narciso de Dorian Gray. Ao adolescentizar-se, o adulto promove um apagamento radical da diferença, a ponto de não mais permitir que o adolescente se veja como tal. Ocorre uma espécie de subtração da condição juvenil do adolescente, que se vê entregue ao desenlace crônico produzido pelo discurso do capitalista: ao consumo banal, à coisificação de si (gadgets), aos excessos pulsionais ou à mecanização cotidiana de suas atitudes. Isso pouco possibilita que de sua força inventiva ou subversiva decante algo novo e genuíno.

Assim, as respostas juvenis à ordem discursiva do mundo adulto, tais como as marcas no corpo, a toxicomania, a erotização extremada, o excesso de internet, o escárnio da autoridade e as provocações de linguagem podem ser, muitas vezes, modos sintomáticos dos jovens lidarem com um real ${ }^{10}$ de difícil elaboração.

\section{Algumas considerações finais}

Sabemos que as condições sociais produzem efeitos psíquicos, sendo a adolescência um momento paradigmático, pois revela o enredo irredutível entre esses dois campos. Assim, o que se decanta desta breve análise da relação da adolescência com o laço social leva-nos a concluir, com Rassial (1997a, 1997b), que a chamada operação psíquica da adolescência acabou sendo um efeito das novas condições sociais dos tempos modernos. Entendemos que o discurso do capitalista, próprio desses tempos, que segrega as diferenças e as objetifica, produzindo uma espécie de adultez erodida sem igual na história, gera uma nebulosa tanto quanto disforme adultez, sem marcos culturais ou significantes claros que a demarque. Temos então a adolescência generalizada como a concebemos aqui.

Se em tempos diferentes dos nossos os rituais culturais ou significantes funcionavam como dispositivos de elaboração das mudanças corporais típicas da puberdade, inscrevendo com legitimidade o novo lugar do sujeito adolescente no cenário social, em nossa época a ausência desses ritos simbólicos de passagem parece deixar os jovens em uma espécie de limbo com relação aos modos de representação de si no social (Ruffino, 1995).

Nesse sentido, a pergunta sobre o inflacionamento imaginário produzido através da figuração do adolescente "empoderado" revela, talvez, aquilo que desaparece nas brumas da ausência de ritos e dispositivos simbólicos da cultura e da posição da adultez contemporânea (Gurski, 2012). Assim, o trabalho psíquico exigido por conta da passagem adolescente demanda do jovem de agora um quantum extra de simbolização, a fim de que possa elaborar tanto o real de seu novo corpo quanto os novos traços que constrói, através da sutil transição entre o campo familiar e o campo social.

Ora, no momento em que o discurso do capitalista se sedimenta e promove o empobrecimento dos laços sociais e o desaparecimento da diferença geracional, em que as práticas culturais decorrentes de tal discurso não oferecem a dose de simbolização suficiente a essa operação tão necessária à passagem adolescente, e, sobretudo, os adultos não conseguem reconhecer a própria experiência como passível de transmissão, acreditamos, com efeito, que se interrompa o elo entre os diferentes tempos. Ou seja, o enlace entre passado, presente e futuro já não possibilita que os mais jovens possam construir o novo a partir da transmissão dos que chegaram antes. Nesse sentido, a ausência de referências e a pane da autoridade de transmissão, como bússola da trilha da vida, situam o jovem em um estado de desamparo simbólico, restando, muitas vezes, as marcas do corpo e a superlativação do Eu como um lugar de marca do sujeito.

É nessa direção que consideramos as configurações da cultura como também responsáveis pelas condições desse desenlace. Na busca de um lugar de enunciação, parecido com um novo nascimento, o adolescente parece sofrer com os efeitos da desmoralização da experiência, da adolescentização generalizada, das diferentes constrições do tempo e da ausência de operatividade da palavra, respondendo a essas condições com o colorido sintomático que já descrevemos. Nesse contexto, é necessário que não nos precipitemos lançando nossos jovens à fogueira dos diagnósticos contemporâneos; afinal, suas adicções, compulsões, hipercinesias, fobias, entre outros modos de sofrimento, talvez não passem de um "tempo de resistência psíquica", ou, dito de outro modo, não passem de uma forma de intervalo necessário para elaborar as condições atuais dessa passagem. 
Torna-se necessária, então, a viabilização de condições passíveis de traduzir, em palavras, aquilo que, muitas vezes, eles só conseguem expressar através da subversão e do sintoma. É nesses momentos de pura volatilidade que o adulto precisa permitir que a palavra seja salvaguardada para que se preserve a experiência, a memória, a lei. É a palavra que tem a potência de conservar as referências, de restabelecer o laço, oferecendo uma proteção imaginária ao construir códigos e delinear um horizonte simbólico de representações. Isso pode bem retirar o caráter de paródia que a posição de saber da adultez contemporânea assumiu no tempo atual.

Quer dizer, é no elo entre tempo, memória, lei e experiência que o adulto tem a possibilidade de ressignificar a posição de suspensão na qual se encontra, viabilizando ao jovem a tomada de seu lugar. $\mathrm{O}$ adulto não é a lei, mas é aquele que, através de si, de sua palavra e memória, lembra que ela está aí a nos simbolizar e humanizar. Isso não é tirania, mas sim escolha. Se há escolha, há possibilidade do novo, da diferença e da palavra - essa que os nomeia. E o que queremos nós, afinal, de nossos jovens, senão vê-los através de suas escolhas exercitarem-se como seres de desejos, seres plenos de promessas?

\section{Notas}

1 Importa esclarecer que empregamos o termo "jovem" ou "juventude" para demarcar o espaço de tempo transcorrido entre a infância e a vida adulta, sendo a "adolescência" sua existência historicamente demarcada em nossos tempos e a "puberdade", o real corporal que a atravessa. Conferir, por exemplo, Freud (1905/1980c), Rassial (1997) e Matheus (2007).

$2 \mathrm{O}$ videoclipe citado é produto do projeto de pesquisa $O$ Sonho Brasileiro, da empresa BOX 1824. Tal pesquisa buscou perfilar os jovens brasileiros entre 18 a 24 anos a fim de pensar as perspectivas de futuro desses sujeitos. Para outros detalhes, conferir http://www.box1824.com.br/.

3 Dylan (1974), Álbum: Planet waves, Asyllum Records, em cuja faixa Forever young podemos ouvir repetidamente o autor nos invocando: "May you stay forever young" ("Que você fique jovem para sempre").

4 Conforme estabelece Rassial (1997a), passamos a consider a condição adolescente não como uma fase cronológica do desenvolvimento, mas como uma das operações psíquicas, ou melhor, a última das operações responsáveis pelo estabelecimento da inscrição ou da forclusão (rejeição) do Nome-do-Pai na constituição psíquica do sujeito.

5 Gurski, R. (2011, agosto). As dobras do tempo e a passagem adolescente na atualidade. Trabalho apresentado no I Congresso Latinoamericano de Psicanálise na Universidade, UERJ. Rio de Janeiro.

6 Lacan, J. (1972). Le savoir du psychanalyste, aula de 06/01/72. Publicação interna da Association Freudienne Internationale. Inédito
O lugar do Outro real é ocupado pelos representantes encarnados do Outro simbólico, em geral pais ou adultos tutelares.

8 A expressão moratória foi introduzida pelo psicanalista Erik Erickson e é utilizada por autores que estudam a juventude e a adolescência na psicologia, sociologia e psicanálise. O psicanalista Contardo Calligaris (2000) utiliza a expressão, mais contemporaneamente, para expressar o hiato que o laço social atual produz entre a maturação do corpo e a assunção de uma posição legítima do jovem no mundo adulto. A polêmica que incide sobre o conceito refere-se a uma discussão quanto à noção de que a expressão revela questões de jovens de classe média e alta, não retratando o processo da juventude como um todo. Para outras problematizações acerca do termo, ver Erickson (1976), Rassial (1997a), Melman et al. (1999), Kehl (2004) e Matheus (2007).

9 O novo aqui é tomado não no sentido da novidade, mas na perspectiva de uma criação do sujeito no campo da significação (Gurski, 2010), ou na direção que Arendt o faz no texto "A crise da educação" (2001).

10 O real é o que não pode ser simbolizado totalmente na palavra ou na escrita, aquilo que "não cessa de não se escrever". O real é um dos três registros que, junto ao simbólico e ao imaginário, fundam o que Lacan denominou de RSI - as instâncias indissociáveis ligadas pelo nó borromeu, que dão conta da relação do sujeito com a falta. O real designa o impossível de ser simbolizado; o simbólico seria o lugar do significante e da função paterna, e o imaginário, o lugar supremo das identificações, lugar das ilusões do eu, da alienação do sujeito. Para outros detalhes, conferir Roudinesco e Plon, 1998.

\section{Referências}

Arendt, H. (2001). Entre o passado e o futuro. São Paulo: Perspectiva.

Calligaris, C. (2000). A adolescência. São Paulo: Publifolha.

Erikson, E. (1976). Identidade, juventude e crise. Rio de Janeiro: Zahar.

Freud, S. (1980a). Contribuições para uma discussão acerca do suicídio. In Edição standard brasileira das obras completas, Vol. 11, pp. 217-219). Rio de Janeiro: Imago. (Original publicado em 1910)

Freud, S. (1980b). O mal estar na civilização. In Edição standard brasileira das obras completas, Vol. 21, pp. 81189). Rio de Janeiro: Imago. (Original publicado em 1930)

Freud, S. (1980c). As transformações da puberdade. Três Ensaios sobre a teoria da sexualidade. In Edição standard brasileira das obras completas, Vol. 7, pp. 129-251). Rio de Janeiro: Imago. (Original publicado em 1905)

Gurski, R. (2010, janeiro/junho). Massacres juvenis e paixão pelo real: o império do sentido e a discussão sobre os impasses do adolescer na atualidade. Revista Psicologia e Política, 10(19), 125-140.

Gurski, R. (2012). A adolescência empoderada. In C. M. M. Farias (Org.), O professor sob pressão: prevenção $e$ enfrentamento da violencia no ambiente de trabalho (pp. 81-90). Porto Alegre: Sinpro/RS.

Kehl, M. R. (2004). A juventude como sintoma da cultura. In R. Novaes \& P. Vannuchi (Orgs.), Juventude e Sociedade: 
trabalho, educação, cultura e participação (pp. 89-114). São Paulo: Fundação Perseu Abramo.

Hobsbawm, E. (2002). Tempos interessantes: uma vida no século $X X$. São Paulo: Companhia das Letras.

Lacan, J. (1992). O seminário. Livro 17: O avesso da psicanálise. Rio de Janeiro: Zahar. (Original proferido em 1969-70)

Lacan, J. (1996). Televisão. Rio de Janeiro: Zahar. (Original publicado em 1974)

Maffesoli, M. (1998). O tempo das tribos. Rio de Janeiro: Forense Universitária.

Matheus, T. C. (2007). Adolescência: história e política do conceito na psicanálise. São Paulo: Casa do Psicólogo.

Melman, C. et al. (1999). O adolescente e a modernidade. Rio de Janeiro: Cia de Freud.

Oliveira, M. C. (s.d.). Vínculos imaginários. Mente \& Cérebro, 2 (Especial: O olhar adolescente), 20-29.

Pereira, M. R. (2006). Isso não é próprio de uma mocinha ou o horror ao feminino. In A. Figueiredo (Org.), Professor, profissão em 3 tempos (pp. 37-51). Ouro Preto, MG: UFOP.

Pereira, M. R. (2011). Acabou a autoridade? Belo Horizonte: Fino Traço/Fapemig.

Rassial, J-J. (1997a). A passagem adolescente: da familia ao laço social. Porto Alegre: Artes e Ofícios.

Rassial, J-J. (1997b). Psicose na adolescência. In Escritos da criança, 4 (pp. 80-96). Porto Alegre: Centro Lydia Coriat.

Roudinesco, E. \& Plon, M. (1998). Dicionário de psicanálise. Rio de Janeiro: Zahar.

Ruffino, R. (1995). Adolescência: notas em torno de um impasse. Revista da Associação Psicanalítica de Porto Alegre, 11, 41-46.

\section{Agradecimentos}

Às agências de fomento CNPq e FAPEMIG. Processos CNPq 470459/2011-5 e 471705/2011-0; e FAPEMIG SHA-APQ-01942-11.
Recebido em: 20/04/2012

Revisão em: 04/02/2013

Aceite em: 15/07/2013

Marcelo Ricardo Pereira é Psicólogo, Psicanalista; Doutor em Psicologia e Educação (USP/Paris13) e Pós-doutor em Psicologia, Psicanálise e Psicopatologia Clínica (USP/Université de Provence). Professor do Departamento de Ciências Aplicadas e da Linha de Pesquisa Psicologia, Psicanálise e Educação, do Programa de Pós-Graduação da Faculdade de Educação da UFMG.

É pesquisador PPM/FAPEMIG, CNPq e coordena o LEPSI/Seção-Minas (Laboratório de Estudos e Pesquisas Psicanalíticas e Educacionais sobre a Infância) e o GT Psicanálise e Educação (ANPEPP). Endereço: UFMG. Av. Antônio Carlos, 6627, FaE, s. 1611. Cid. Universitária. Pampulha. Belo Horizonte/MG, Brasil. E-mail: $\underline{\text { mrp@,fae.ufmg.br }}$

Rose Gurski é Psicanalista; Doutora em Educação (UFRGS); Professora do Departamento de Psicanálise e Psicopatologia do Instituto de Psicologia UFRGS e do Programa de Pós-Graduação em Psicanálise: Clínica e Cultura (UFRGS). Coordenadora do NEPÉIA/UFRGS e membro do GT Psicanálise e Educação (ANPPEP). E-mail: rosegurski@ufrgs.br

\section{Como citar:}

Pereira, M. R. \& Gurski, R. (2014). A adolescência generalizada como efeito do discurso do capitalista e da adultez erodida. Psicologia \& Sociedade, 26(2), 376-383. 